\title{
Aggressive extracorporeal shock wave lithotripsy of gall bladder stones within wider treatment criteria: fragmentation rate and early results
}

\author{
G Meiser, M Heinerman, G Lexer, O Boeckl
}

\begin{abstract}
Two hundred and twenty patients with a total of 412 gall bladder stones of between 8 and $38 \mathrm{~mm}$ in size were treated with extracorporeal shock wave lithotripsy, using the overhead module Lithostrar Plus. Fifty six per cent of stones were solitary (mean (SD) diameter 23 (5) $\mathrm{mm}$ ) and $9.5 \%$ of the patients had more than three stones. Stones were successfully disintegrated in 218 patients (fragmentation size $<5 \mathrm{~mm}$ in $80 \%,<10 \mathrm{~mm}$ in $19 \%$ ). Some $65 \%$ of patients required one treatment and the rest two or three. A mean (SD) of 4100 (1800) shock waves with a pressure of 700 bar were applied. Twenty four to 48 hours after lithotripsy a transient but significant increase in serum transaminase activities (31\%) and in bilirubin (29\%), urinary amylase $(27 \%)$, and blood leukocyte $(62 \%)$ values was observed. In $29 \%$ of patients there was a transient microhaematuria, in $2 \%$ transient macrohaematuria, and in $25 \%$ painless petechiae of the skin. Ultrasound showed temporary gall bladder wall oedema in $13 \%$, temporary distension of the gall bladder in $11 \%$, and transient common bile duct distension in $8 \%$ after treatment. After discharge from hospital, $31 \%$ of patients complained of recurrent colic that responded to simple analgesics. Four to eight weeks after therapy, four patients developed biliary pancreatitis and 11 biliary obstruction that was managed by endoscopy. To date, 105 patients have been followed for over 12 months. Sixty one of these had a solitary stone, 17 had two, and 27 had three or more stones. A total of 59 patients, including 44 with a primary solitary stone, eight with two stones, and seven with three or more stones are completely stone free.
\end{abstract}

1st Surgical Department and Ludwig-BoltzmannInstitute for Experimental and Gastroenterological Surgery,

Landeskrankenanstalten, Salzburg, Austria

$\mathrm{G}$ Meiser

$M$ Heinerman

G Lexer

O Boeckl

Correspondence to:

Dr G Meiser, I. Chirurgische Abteilung,

Landeskrankenanstalten

Salzburg, Muellner

Hauptstrasse 48, A-5020

Salzburg, Austria.

Accepted for publication

31 December 1990
Extracorporeal shock wave lithotripsy (ESWL) is a new treatment that has overtaken surgery as a first line therapy for some patients with gall bladder stones. Initial multicentre studies of ESWL have shown that this technique is successful in the short term and promising in the long term. Treatment success depends on adhering to rigid patient selection criteria, attention to technical details, and the experience of the attending physician.

We report our preliminary results of ESWL treatment using the Lithostar Plus in a surgical department. Not only have the commonly accepted indications for ESWL been widened, but we have also attempted to achieve a high fragmentation rate by applying more shock waves with a higher energy level and more treatment sessions within a short time.

\section{Patients and methods}

\section{SELECTION}

Patients with symptomatic gall bladder stones were admitted to the lithotripsy programme. Diagnosis of stones and estimation of their size were always achieved by ultrasound in fasted patients. Patients were examined in the right and left lateral and supine positions as well as erect. A stone diameter between 0.8 and $3.8 \mathrm{~cm}$ and a total stone volume not exceeding $50 \%$ of the total gall bladder volume were criteria for this treatment.

All patients had a plain radiograph of the right upper abdominal quadrant to differentiate calcified concretions. Intact contractile function of the gall bladder, with regular emptying, was an absolute requirement. A gall bladder volume reduction of at least $40 \%$, determined by ultrasound one hour after swallowing a meal stimulant (raw egg), was required. Because the presence of an acute gastroduodenal ulcer was viewed as an absolute contraindication, all patients underwent oesophagogastroduodenoscopy on the day before ESWL. Further exclusion criteria were hepatopathies (hepatitis, cirrhosis, cystic liver), coagulopathies, abdominal vascular anomalies, acute cholecystitis, acute pancreatitis, and biliary obstruction. Finally, the ability to localise stones below the costal arch was imperative.

PATIENTS

Two hundred and twenty patients fulfilled our selection criteria and were admitted to the study; 513 were excluded. One hundred and thirty two women and 88 men aged between 16 and 91 years with a mean (SD) age of 75 (24) years were treated. The onset of symptoms of gall stones had occurred $5.5(2.3)$ years previously. The mean (SD) size of the stones was $19(6) \mathrm{mm}$. A total of 412 stones were found in these patients 124 had a solitary stone and 118 had between two and a maximum of five radiolucent stones.

\section{CONCOMITANT LITHOLYSIS THERAPY}

Fourteen days before ESWL, the patients received $10 \mathrm{mg} / \mathrm{kg}$ body weight daily of both cheno- and ursodesoxycholic acid as single bedtime doses. This treatment was continued until there was total ultrasound and radiological disappearance of the stones after ESWL. 
laboratory investigations were undertaken: haemoglobin, erythrocytes, leukocytes, thromboctyes, prothrombin time, serum glutamic oxalo-acetic transaminase, serum glutamic pyruvic transaminase, $\gamma$ glutamyl transferase, alkaline phosphatase, bilirubin, serum and urinary amylase, serum lipase, and urinalysis. These investigations were repeated six hours and one to three days after ESWL.

\section{PHYSICAL AND ULTRASOUND CONTROL}

\section{EXAMINATIONS}

A second examiner verified the success of fragmentation with ultrasound on days one and two after ESWL. A physical examination was also performed. There were further follow up examinations four, 12, 20, 28, and 36 weeks after ESWL.

\section{TECHNICAL AND TACTICAL DETAILS}

We used a lithotriptor of a second generation (Lithostar Plus, Siemens Company) with which stone localisation is made possible by an integrated ultrasound system as well as an $x$ ray system. The generation of shock waves can be controlled by either of two independent modules located below the table or overhead with an internal mobile ultrasound scanner. The shock wave generation ( 90 per minute) results from the high voltage induced movements of an electromagnetic coil which are transmitted onto a metallic membrane. The shock wave energy is focused with an acoustic lens through a water chamber. Pressure values of approximately $\mathbf{6 0 0}$ to 700 bar are thus achieved in the focus zone $(4 \times 40 \mathrm{~mm})$.

All patients were treated with the 'overhead' module. For optimal contact between the lithotriptor head and the surface of the body, ultrasound gel (Gerosonic) was used. During treatment, the patient remained in the left lateral position, stabilised by a vacuum mattress. After adaptive application of 50 shock waves at a 'low energy' setting of 5 ( 350 bar), followed by 50 shock waves at an energy level of 7 (500 bar), we treated all patients with the highest energy level of 9 (700 bar). If no stones or residual fragments were found after fragmentation, the patient was moved into the prone, right, lateral, and supine positions for five to 10 minutes each to shift any hidden concretions so that they could be localised. Our end goal was a fragment size $<5 \mathrm{~mm}$. If the first treatment did not achieve this result (maximum shock wave number of 6000 ), second and third sessions (if needed) were given in the days immediately afterwards.

\section{Results}

FOCUSING AND FOCUSING TIME

In 185 patients we were able to localise the gall stones with ultrasound within a mean (SD) time of 2 (1) minutes using the 'overhead' module. In 35 patients the gall bladder was hidden under the costal arch and optimal focusing could only be achieved by deep inspiration or with voluntary downward abdominal expansion. Focusing time
TABLE I Stone characterisation and applied shock waves in patients with gall bladder stones. (Values, mean $(S D)$.)

\begin{tabular}{llll}
\hline $\begin{array}{l}\text { No of } \\
\text { stones }\end{array}$ & $\begin{array}{l}\text { No of } \\
\text { patients }\end{array}$ & Stone size $(\mathrm{mm})$ & $\begin{array}{l}\text { No of shock waves } \\
(1200-12000)\end{array}$ \\
\hline 1 & 124 & $\begin{array}{c}10(38) \\
23(5)\end{array}$ & $3600(1600)$ \\
2 & 43 & $\begin{array}{c}8(30) \\
18(4)\end{array}$ & $4200(1500)$ \\
3 & 22 & $\begin{array}{c}8(28) \\
12(6)\end{array}$ & $5800(2000)$ \\
4 & 19 & $\begin{array}{c}8(10) \\
10(5)\end{array}$ & $4900(1900)$ \\
5 & 12 & $\begin{array}{c}6(10) \\
9(6)\end{array}$ & $4900(1200)$ \\
Total 412 & 220 & $19(6)$ & $4100(1800)$ \\
\hline
\end{tabular}

TABLE II Number of treatment sessions in patients with different numbers of stones

\begin{tabular}{lrrrrrr}
\hline & \multicolumn{2}{l}{ No of stones } \\
\cline { 2 - 7 } No of treatments & 1 & \multicolumn{1}{c}{2} & \multicolumn{1}{c}{3} & \multicolumn{1}{c}{4} & 5 & Total \\
\hline 1 & 96 & 22 & 11 & 8 & 7 & 144 \\
2 & 24 & 19 & 7 & 9 & 3 & 62 \\
3 & 4 & 2 & 4 & 2 & 2 & 14 \\
Total 296 & 123 & 43 & 22 & 19 & 12 & 220 \\
\hline
\end{tabular}

in these patients was 7 (2) minutes. Because of the resultant fragmentation we had to refocus seven to 35 times (mean (SD) 25 (11)). It was then necessary to reposition the patient two to six times.

In this study between 1200 and 12000 shock waves (mean (SD) 4100 (1800)) were applied (Table I). Patients with solitary stones required significantly fewer shock waves than those with two or more stones (Student's $t$ test). In total, 296 treatments were necessary in the 220 patients (Table II). One treatment session was sufficient for adequate fragmentation in 144 patients and the remainder required two or more sessions (Table II).

\section{DRUG TREATMENT}

Forty three patients required no medication for pain during ESWL, 75 patients were premedicated with $50 \mathrm{mg}$ pethidine and $5 \mathrm{mg}$ diazepam, while 97 patients required $100 \mathrm{mg}$ pethidine and $5 \mathrm{mg}$ diazepam. The remaining patients needed $200 \mathrm{mg}$ pethidine and $10 \mathrm{mg}$ diazepam for adequate pain control. Because adequate analgesia was maintained, all patients remained conscious during treatment and were able to provide feedback regarding any pain suffered.

\section{FRAGMENTATION RESULTS}

In 176 patients we achieved an acceptable fragmentation size of $<5 \mathrm{~mm}$ during treatment (Figs 1-3). In 42 patients a minimum fragmentation size of $10 \mathrm{~mm}$ was achieved. Two patients each had a large stone $(3.5 \mathrm{~cm})$ that could not be fragmented despite a total application of 12000 shockwaves. They underwent operation five days after ESWL treatment. There was no macroscopic or histopathological evidence of gall bladder abnormality as a result of ESWL treatment in these patients and the large cholesterol stones were totally intact. 


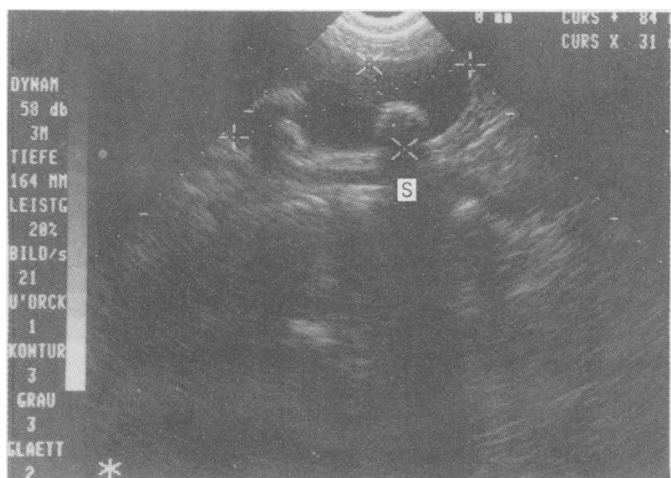

Figure 1: Solitary gall bladder stone $(S)$ before extracorporeal shock wave treatment.

DURATION OF TREATMENT SESSION

Each treatment session took 40 to 140 minutes (mean (SD) 80 (25) minutes). Increased experience with use of the instruments led to a noticeable reduction in the treatment time.

ULTRASOUND FINDINGS AFTER ESWL

Two to 18 (1317 in total) ultrasound scans were performed in all patients (mean (SD) 6 (3)). Particular attention was paid to the functioning of the gall bladder. In no case was a decrease in contractibility detected - not even in the 29 patients who showed transient gall bladder wall oedema, as evidenced by a thickness of 5 to $10 \mathrm{~mm}(8(2) \mathrm{mm})$ after ESWL. This oedema resolved fully within 48 hours. Twenty four patients developed a dilated gall bladder immediately after ESWL. Seventeen other patients developed common bile duct dilatation; it increased from a baseline value of 4 to $5 \mathrm{~mm}$ diameter before ESWL to 7 to $8 \mathrm{~mm}$ afterwards (mean (SD) 8 (1) mm, statistically not significant, Student's $t$ test) without clinical findings or on laboratory test results suggestive of biliary obstruction. All these ultrasound findings resolved within two days.

\section{CLINICAL AND LABORATORY FINDINGS}

After ESWL, a variety of clinical abnormalities were observed: transient microhaematuria, beginning six hours after ESWL (29\%); macrohaematuria (2\%); and skin petechiae overlying the area of ESWL application (25\%).

After discharge from hospital, recurrent

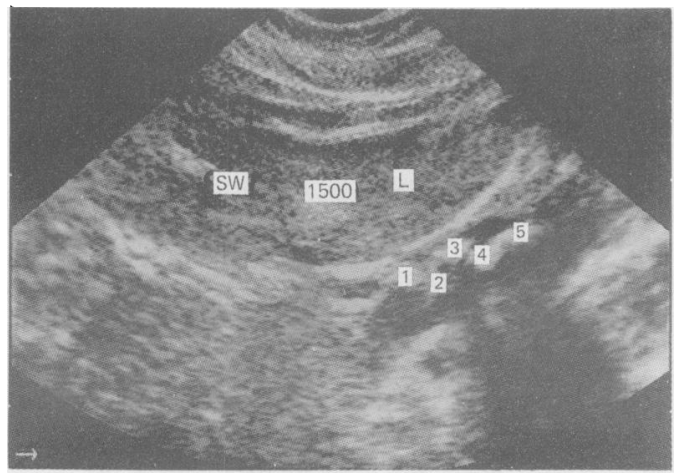

Figure 2: Stone fragmentation after 1500 shock waves $(S W)$ with energy level 9 ( 700 bar $) ; L=$ liver, $1-5=$ number of resulting fragments.

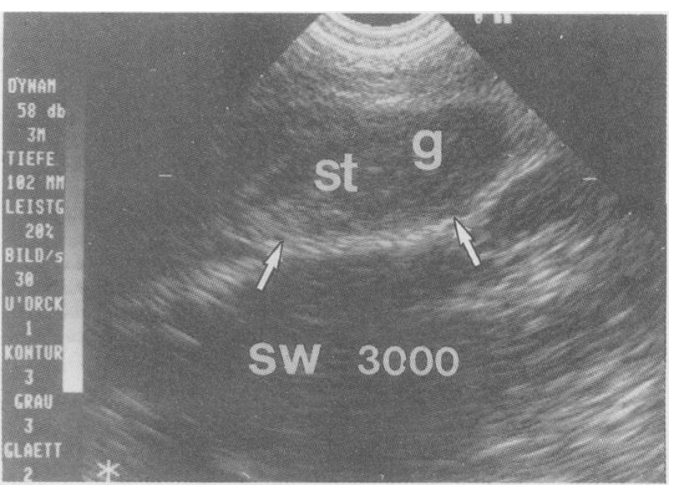

Figure 3: Complete stone distintegration of the solitary gall bladder stone in mutliple fragments $($ st $)$ smaller than $3 \mathrm{~mm}$ gall bladder stone in mutliple fragments $($ after 3000 shock waves; $g=$ gall bladder.
a

colicky pain in the upper abdomen was reported by 68 patients at follow up. This pain responded to spasmolytic treatment with hyoscine butybromide suppositories (Buscopan). A more serious sequellum, biliary pancreatitis, was observed in four patients two to eight weeks after ESWL. In three endoscopic papillotomy with stone extraction was necessary (Table III), but no further operation was required.

The size of the stones we removed was between 3 and $7 \mathrm{~mm}$ : in one patient the stone had passed spontaneously through the papilla. Clinical findings and laboratory test results showed that acute pancreatitis resolved within two weeks.

Another 11 patients showed ultrasound and laboratory signs of biliary obstruction with an increase in the bilirubin concentration of up to $10 \mathrm{mg} / 100 \mathrm{ml}$. In only five patients were residual stone fragments (of 5 to $7 \mathrm{~mm}$ ) found in the common bile duct. These were easily removed by endoscopic papillotomy (EPT) and endoscopic retrograde extraction. In three patients EPT was necessary because of a stenosis of the papilla, diagnosed by endoscopic retrograde cholangiopancreatography.

Important abnormalities of differing extents and varying frequencies were found in laboratory investigations (leukocyte counts, serum bilirubin, transaminases and $\gamma$ glutamil transferase, and urinary amylase). No correlation with the number of shock waves applied could be determined. All these abnormal values returned to baseline within three days (Table IV).

\section{SHORT TERM RESULTS}

At present, 105 patients have been followed for over 12 months. Sixty one of these patients had had a solitary stone, 17 had had two stones, and 27 had had three or more stones. We were able to verify the total absence of stones in 59 patients (Table V).

\section{Discussion}

The percentage of patients with gall stones who are eligible for ESWL has yet to be scientifically defined and clarified. Rates vary from 10 to $30 \%$ and reflect the referal population..$^{1-10}$ Our own results yield a rate of $30 \cdot 3 \%$. This is because we included for the first time patients with more than three stones $(n=32)$ and a stone size of up to 
TABLE III Complications after extracorporeal shock wave lithotripsy (ESWL)

\begin{tabular}{lll}
\hline Complication & No of patients & Management (no) \\
\hline Jaundice, biliary obstruction & 11 & ERCP (11), EPT (8), stone removal (5) \\
Biliary pancreatitis & 4 & EPT (4), stone removal (3) \\
Duodenal ulcer & 1 & Conservative \\
Minor stroke & 1 & Conservative \\
Total & 17 & \\
\hline
\end{tabular}

$\mathrm{ERCP}=$ endoscopic retrograde cholangiopancreatography: EPT = endoscopic papillotomy.

TABLE IV Laboratory findings after extracorporeal shock wave lithotripsy (ESWL)

\begin{tabular}{|c|c|c|c|c|c|}
\hline Laboratory data & $\begin{array}{l}\text { Normal } \\
\text { range }\end{array}$ & $\begin{array}{l}\text { Initial } \\
\text { value } \\
(\text { mean } \\
(S D))\end{array}$ & $\begin{array}{l}\text { After } \\
\text { ESWL } \\
(\text { mean } \\
(S D))\end{array}$ & $\mathrm{No}(\%)$ & $\begin{array}{l}\text { No shock } \\
\text { waves } \\
\text { (mean } \\
(S D))\end{array}$ \\
\hline Leukocytes $\left(10^{4} / 1\right)$ & $6000-8000$ & $6300(1500)$ & $8900(2600)$ & $136(62)$ & $4100(2000)$ \\
\hline $\begin{array}{l}\text { Glutamic oxalo-acetic } \\
\text { transaminase }(\mathrm{U} / \mathrm{l})\end{array}$ & 10-15 & $12(4)$ & $35(13)$ & $68(31)$ & $3900(1500)$ \\
\hline $\begin{array}{l}\text { Glutamic pyruvic transaminase } \\
(\mathrm{U} / \mathrm{l}) \\
\gamma \text { Glutamil transferase }(\mathrm{U} / \mathrm{l}) \\
\text { Bilirubin }(\mu \mathrm{mol} / \mathrm{l}) \\
\text { Urinary amylase }(\mathrm{U} / \mathrm{l})\end{array}$ & $\begin{array}{l}10-17 \\
15-28 \\
1 \cdot 7-17 \cdot 1 \\
32-500\end{array}$ & $\begin{array}{l}13(5) \\
12(8) \\
10 \cdot 3(3 \cdot 4) \\
98(56)\end{array}$ & $\begin{array}{l}33(15) \\
87(37) \\
30 \cdot 8(8 \cdot 5) \\
270(100)\end{array}$ & $\begin{array}{l}64(29) \\
29(13) \\
64(29) \\
59(27)\end{array}$ & $\begin{array}{l}3700(2000) \\
3700(1800) \\
3800(1500) \\
4000(1400)\end{array}$ \\
\hline
\end{tabular}

$38 \mathrm{~mm}(\mathrm{n}=27)$ in the ESWL protocol. Thus, $27 \%$ of our patients would not have fulfilled established criteria for ESWL. ${ }^{21112}$ We evaluated stone size and number, as well as gall bladder function, by ultrasound similar to the method of Ell et al.

Only for the verification of stone calcification did we require plain radiographs of the right upper abdominal quadrant. Computed tomography was not necessary, although about $20 \%$ of radiolucent stones can be visualised as calciferous by this diagnostic procedure. ${ }^{13-18}$

The efficacy of ESWL combined with oral chemolysis using ursodesoxycholic and chenodesoxycholic acid has not yet been proved. ${ }^{218-20}$ Published reports on chemolysis emphasise that stone clearance is strictly dependent on stone size. ${ }^{1-35101121}$ Because of this good disintegration results of ESWL treatment seem to be a good basis for adjuvant bile acid therapy. ${ }^{21+17-25}$

The focusing time, defined as the time necessary to focus on the stone(s) to be treated, has been mentioned infrequently in publications until recently. In our learning phase we needed up to 25 minutes for stone targeting, which was reduced to 2 (1) minutes over time. Furthermore, it is necessary to refocus several times ( 25 (11) times per patient) because of hidden multiple concretions or fragments. There are few data on focusing times in the reports from other authors.

The duration of treatment in our patients was mean (SD) 80 (25) minutes, which was clearly

TABLE V Patients free of stones after extracorporeal shock wave lithotripsy in relation to primary stone number and size

\begin{tabular}{llll}
\hline $\begin{array}{l}\text { No of } \\
\text { stones }\end{array}$ & $\begin{array}{l}\text { No patients at } 12 \\
\text { mths follow up }\end{array}$ & No\% stone free & $\begin{array}{l}\text { Mean }(S D) \text { stone } \\
\text { size }(\mathrm{mm})\end{array}$ \\
\hline 1 & 61 & $44(72)$ & $1(28)$ \\
2 & 17 & $8(47)$ & $21(6)$ \\
$8) 30)$ \\
3 & 11 & $3(27)$ & $15(7)$ \\
$8(22)$ \\
4 & 16 & $4(25)$ & $15(5)$ \\
& 105 & $59(56)$ & $13(5)$ \\
Total & 10 & & \\
\hline
\end{tabular}

longer than that reported by other groups. ${ }^{16}$ Technical differences and, most importantly, differences in shock wave frequency, number, and energy are responsible for this. - $^{1-35611122627}$ In our group an average of 4100 shock waves at 700 bar were applied. This correlates with the findings of other investigators using the same instrument, ${ }^{37132627}$ but exceeds the number of shock waves applied by groups working with higher pressures but a lower number of shock waves. ${ }^{2561112}$ In the Munich group, $83 \%$, and in Ell's group, $78 \%$ of treated stones were single stones. ${ }^{125}$ In our study, only $56 \%$ of patients had solitary stones and the mean stone size of 23 (5) mm was larger than that in the Munich study (19 (5) $\mathrm{mm}$ ). As expected, these patients and 53 patients with three, four, or more stones required longer treatment.

The efficacy of different lithotriptor machines can be measured objectively according to fragmentation results, In $80 \%$ of our patients, the primary stone(s) could be disintegrated to size $<5 \mathrm{~mm}$, and in $20 \%$ to $<10 \mathrm{~mm}$. These sizes were confirmed by repeated ultrasound examinations in days following treatment in patients in various positions, and by a different examiner using a $5 \mathrm{MHz}$ transducer.

The number of treatment sessions correlates significantly with stone number and, of course with the primary fragmentation results, ${ }^{1251112}$ as we showed in our study. In $35 \%$ of our patients a second or third session was necessary.

General anaesthesia, as practised in the early stage of ESWL by the Munich group," is obsolete today. We give analgesic medication $^{1-35-711-132627}$ during therapy to all patients regardless of the type of lithotriptor, although Piezoelectric machines do not cause much pain for technical reasons. ${ }^{5}$

A critical analysis of ESWL treatment results must include inherent side effects and complications. In our study, transient microhaematuria (in $29 \%$ ) and skin petechiae (in $25 \%$ ) were found and were not correlated to the number of shock waves. These side effects have been reported by other authors in varying frequency. ${ }^{1-3561326-28}$

An appreciable temporary increase in blood leukocytes, serum transaminases, serum bilirubin, and urine amylase was seen. These changes have rarely been reported by other authors. ${ }^{1213}$ We observed by ultrasound (also without correlation to the number of shock waves) oedema of the gall bladder wall in $13 \%$ of our patients and, surprisingly, common bile duct dilatation without laboratory chemistry proof of cholestasis in $8 \%$. Although changes in the gall bladder wall after ESWL have been noted, 12529 dilatation of the common bile duct seems to be a side effect that has not previously been reported. Possible late biliary complications ${ }^{121330}$ necessitate competence in endoscopic management by every department performing ESWL. In this study four patients developed biliary pancreatitis, which was treated without difficulty by EPT and stone removal in three. Comparable complication rates for biliary pancreatitis are also reported by other groups. ${ }^{1-35-7} 13$

Our preliminary overall results showing complete stone disappearance in $56 \%$ (59 of 148 
patients followed over 12 months) seem to show only modest success. They differ significantly from the data published by the Munich group. In addition, the primary disintegration results from Munich ${ }^{\prime}$ and Salzburg differ significantly. In this context, we question the ability of the Munich group' to measure exactly such tiny fragments (for example mean (SD) $2 \cdot 4(1 \cdot 1) \mathrm{mm}$ ) while admitting, at the same time, that they had diagnostic difficulties because of clouds of fragments after ESWL.

It must be remembered that the stone size and the total stone volume are important determinants of the clearance time of the gall bladder after lithotripsy, as has been clearly pointed out by Sackmann et al. ' We can only confirm these facts by our own experience, which gave a stone free rate in patients with solitary stones of $72 \%$ and in those with two stones of $47 \%$ at one year. Therefore our patients with significantly more and bigger stones and also with fragments of about $5 \mathrm{~mm}$ after ESWL obviously require a longer follow up before the results can be discussed confidently.

Further ultrasound and radiological examinations will show if we were correct to broaden our inclusion criteria for lithotripsy. Our stone fragmentation rate, seems to be as good as that of the Munich group' and we are therefore optimistic.

1 Sackmann M, Delius M, Sauerbruch T, et al. Shock-wave lithotripsy of gallbladder stones. The first 175 patients. NEnglf Med 1988; 318: 393-7.

2 Sackmann M, Sauerbruch T, Holl J, Paumgartner G. Gallstone treatment by extracorporeal shock-wave lithotripsy. fHepatol 1988; 17: 283-7.

3 Staritz M, Hagenmueller F. Gallensteinbehandlung durch extrakorporale Sto $\beta$ wellen-Lithotripsie und adjuvante Lyse. Standort und Perspektive. Internist 1988; 29: 792-5.

4 Bouchier JAD, Non-surgical treatment of gallstones: many contenders but who will win the crown? Gut 1988; 29: 13744.

5 Ell C, Kerzel W, Heyder N, et al. Piezoelektrische Lithotripsie von Gallenstenen. Erste klinische Erfahrungen. Dtsch Med Wochenschr 1988; 133: 1503-7.

6 Greiner L, Wenzel H, Jakobeit C. Biliäre StoßwellenLithotripsie. Fragmentation und Lyse - ein neues Verfahren. Dtsch Med Wochenschr 1987; 112: 1893-6.

7 Burhenne JH, Becker CD, Malone DE, Raweit B, Fache JS Biliary lithotripsy: early observations in 106 patients. Work in process. Radiology 1989; 171: 363-7.

8 Heberer G, Paumgartner G, Sauerbruch T, et al. A retrospective analysis of 3 years' experience of an interdisciplinary approach to gallstone disease including shockwaves. Ann Surg 1988; 208: 274-8.
9 Brink JA, Simeone JF, Müller PR, Richter JM, Prien EL, Ferrucci JT. Physical characteristics of gallstones removed at cholecystectomy: implications for extracorporeal shockwave lithotripsy. AfR 1988; 151: 927-31.

10 Ferrucci JT. Biliary lithotripsy. $A \mathcal{F} R$ 1989; 153: 15-22.

11 Sauerbruch T, Delius M, Paumgartner G, et al. Fragmentation of gallstones by extracorporeal shock-waves. $N E n g l f$ Med 1986; 314: 818-22.

12 Sauerbruch T, Paumgartner G. Therapies der Cholecystolithiasis. Internist 1986; 27: 643-55.

13 Hagenmueller F, Neuhaus H, Brandstetter K, Gerhardt $P$ Classen $M$. Gallstone disintegration by electromagnetic ESWL. Abstract book of the 2nd Interdisciplinary International Symposium on Biliary Lithotripsy. Vancouver

14 Dowling RH. Cholelithiasis: medical treatment. Clin Gastroenterol 1982; 12: 125-69.

15 Baron RL, Rohrmann CA, Lee SP, Shumann WP, Teefey SA CT evaluation of gallstones in vitro: correlation with chemical analysis. $A \mathscr{f} R$ 1988; 151: 1123-8.

16 Chaussy CH, Brendel W, Schmidt E. Extracorporeally induced destruction of kidney stones by shock-waves. Lancet 1980 ii: $1265-8$.

17 Fromm H. Ursodesoxycholic acid for adjuvant therapy with extracorporeal shockwave lithotripsy of gallstones. $\mathcal{f}$ Clin Gastroenterol 1988; 10 (suppl 2): 18-21.

18 Fromm H. Gallstone dissolution therapy. Current status and future prospects. Gastroenterology 1986; 91: 1560-7.

19 Vanderpool D, Jones RC, O'Leary JP, Hamilton JK Steinbach HS. Biliary lithotripsy in the United States. South Med F 1989; 82: 636-9.

20 Vergunst H, Terpstar OT, Brakel K, Dick JA, Mallison CN Extracorporeal shockwave lithotripsy of gallstones: possibilities and limitations. Ann Surg 1989; 210: 565-75.

21 Schoenfield LJ, Lachin JM. NCGS Steering committee and the NCGS Group National Cooperative Gallstone Study. A controlled trial of the efficacy and safety of menodeoxycholic acid for dissolution of gallstones. Ann Intern Med 1981; 95 : 257-82.

22 Neubrand M, Sauerbruch T, Stellaard F, Paumgartner G. In vitro cholesterol gallstone dissolution after fragmentation vitro cholesterol gallstone dissolution afte
with shock-waves. Digestion 1986; 34:51-9.

23 Weis HJ, Holtermüller KH, Gilschof P. Gallstone dissolution with chenodeoxycholic acid. Klin Wochenschr 1980; 58: 313

24 Podda M, Zuin M, Dioguordi ML, Festorazzi S, Arrigoni E Combined administration or ursodeoxycholic $(\mathbf{u})$ and chenodeoxycholic (c) acid: a more effective way to dissolve radiolucent gallstones. Gastroenterology 1983; 84: 1274-8.

25 Maton PN, Iser JH, Reuben A, et al. The final outcome of CDCA-treatment in 125 patients with radiolucent gallstones: factors influencing efficacy. Withdrawal, symptoms and side effects and post-dissolution recurrence. Medicine 1982; 61: 85-96.

26 Staritz M, Kümmerle F Extrakorporale StoßwellenLithotripsie von Gallensteinen und die Rolle der Lithotripsie von Gallensteinen und die Rolle der

27 Staritz M. Floth A, Buess G, et al. Extracorporeal shock waves (ESW) for gallstone fragmentation. First in-vitro experience with a second generation device working without waterbath Abstract] Gastroenterology 1987; 92: 1652 .

28 Hood KA, Keightley A, Dowling RH, et al. Piezo-ceramic lithotripsy of gallbladder stones: initial experience in 38 patients. Lancet 1988; i: 1322-4.

29 Ponchon T, Martin X, Mestas JL, Cathignol D, Lambert R, Extracorporeal lithotripsy of gallstones. Lancet 1987 ii: 448

30 Teichmann RK, Sauerbruch T, Sackmann M, Holl J, Paumgartner G, Herberer G. Surgical intervention following fragmentation of gallstones by extracorporeal shock waves. World f Surg 1989; 13: 317-20. 